\title{
AVALIAÇÃO DO CRESCIMENTO FOLIAR E RADICULAR DE MUDAS MICROPROPAGADAS DO ABACAXIZEIRO CV. GOLD EM ACLIMATAÇÃO
}

\author{
EVALUATION OF THE FOLIAR AND RADICULAR GROWTH \\ OF THE MICROPROPAGATED PLANTLETS OF \\ THE PINEAPPLE CV. GOLD IN ACCLIMATATION
}

\author{
Izaias dos Santos Bregonci ${ }^{1}$; Edvaldo Fialho dos Reis ${ }^{2}$; \\ Gustavo Dias de Almeida ${ }^{3 *}$; Vitor José Brum ${ }^{4}$; Moises Zucoloto
}

\begin{abstract}
RESUMO
O experimento foi conduzido em casa de vegetação, no Campus do Centro de Ciências Agrárias da Universidade Federal do Espírito Santo, localizado no município de Alegre-ES, Brasil. Objetivou-se com este trabalho avaliar o crescimento foliar e radicular de mudas micropropagadas de abacaxizeiro cv. Gold [Ananas comosus (L.) Merrill] em fase de aclimatação. O experimento foi montado em esquema de parcela subdividida, avaliando-se o crescimento desse genótipo em 5 diferentes idades de retirada da casa de vegetação de pré-aclimatação: $0 ; 1 ; 2 ; 3$; e 4 meses e a testemunha que aí permaneceu por 5 meses, consistindo-se nas parcelas e avaliações aos: $0 ; 30 ; 60 ; 90 ; 120$ e 150 dias após transplantio, formando as subparcelas. Observa-se que, nas condições do experimento, as mudas micropropagadas podem ser retiradas da casa de vegetação com 1 e 2 meses de pré-aclimatação.
\end{abstract}

Palavras-chave: Abacaxi, Ananas comosus, micropropagação, crescimento.

\begin{abstract}
The experiment was carried out in a greenhouse, in the Centro de Ciências Agrárias da Universidade Federal do Espirito Santo, located in Alegre city, Brazil. The work had as objective to evaluate the foliar and radicular growth of micropropagated plantlets of the pineapple cv. Gold [Ananas comosus (L.) Merrill] in phase of the acclimatation. The experiment was set up in arrangement of split plot, being evaluated the growth of that genotype in 5 different ages of retreat of the greenhouse of pre-acclimatation: 0; 1; 2; 3 and 4 months and the witness that stayed there for 5 months, consisting in plots and evaluations to the: 0; 30; 60; $90 ; 120$ and 150 days after transplanted, forming the subplots. It was observed that in the conditions of the experiment the micropropagated plantlets can be removed of the greenhouse with 1 and 2 months of pre-acclimatization.
\end{abstract}

Key words: Pineapple, Ananas comosus, micropropagation, growth.

\section{INTRODUÇÃO}

A micropropagação ou cultura de tecidos é uma alternativa viável para produção massal de material propagativo de abacaxizeiros, não só para produção de mudas sadias das cultivares comerciais susceptíveis à fusariose (ALBUQUERQUE et al., 2000), mas também para multiplicação de novos

1 Instituto Capixaba de Pesquisa, Assistência Técnica e Extensão Rural - INCAPER, Alegre-ES, Brasil, CP 16, CEP.: 29500-000. E-mail: izaias@incaper.es.gov.br

2 Depto. de Engenharia Rural do Centro de Ciências Agrárias-Universidade Federal do Espírito Santo (CCA-UFES). Alegre-ES, Brasil.E-mail:edreis@cca.ufes.b

3* PIBIC/UFES, Centro de Ciências Agrárias-Universidade Federal do Espírito Santo (CCA-UFES), Dept ${ }^{\circ}$ de Produção Vegetal, Alegre-ES, Brasil. E-mail: gustavo.ccaufes@hotmail.com

4 Produção Vegetal, Centro de Ciências Agrárias-Universidade Federal do Espírito Santo (CCA-UFES), Alegre-ES, Brasil. E-mail: vitor-ms@cca.ufes.br

5 Produção Vegetal, Centro de Ciências Agrárias-Universidade Federal do Espírito Santo (CCA-UFES), Alegre-ES. E-mail: moizeszucoloto@ hotmail.com

Fecha de Recepción: 10 Julio 2007

Fecha de Aceptación: 07 Diciembre 2007 
genótipos produzidos em programas de melhoramento genético, objetivando reduzir o tempo de lançamento de cultivares (Cabral \& Coppens D'eeckenbrugge, 2002).

Diversos trabalhos científicos a respeito de micropropagação de plantas têm atribuído o mesmo significado aos termos aclimatização e aclimatação. Mas, embora se assemelhem, apresentam conotações distintas. A aclimatização trata dos processos para a passagem de uma planta ou organismo que está in vitro para o ambiente, definido como a adaptação climática da planta para um novo ambiente, sendo todo o processo realizado artificialmente. Por outro lado, a aclimatação tem um significado similar, entretanto, é um processo nos quais plantas ou outros organismos se tornam ajustados a um novo clima ou situação, sendo esse processo essencialmente natural (Guerra \& Nodari, 2006).

Segundo Cunha (1999), a faixa ideal para crescimento e o desenvolvimento das raízes e folhas do abacaxizeiro está compreendida entre $22^{\circ} \mathrm{C}$ e $32{ }^{\circ} \mathrm{C}$. Esse autor cita que o crescimento do abacaxizeiro é reduzido quando há predominância de temperaturas baixas e o termoperíodo influencia a elongação da folha central, reduzindo-a em 53,3\% quando passa de $30^{\circ} \mathrm{C} / 26^{\circ} \mathrm{C}$, respectivamente dia e noite, para $22^{\circ} \mathrm{C} / 18^{\circ} \mathrm{C}$ e, também, a produção de matéria seca da planta foi reduzida em $20 \%$ no período observado, denotando uma alta capacidade de adaptação. Registrou ainda que houve aumento de peso da planta com aumento da temperatura no meio enraizante, quando esta passou de $20^{\circ} \mathrm{C}$ para $25^{\circ} \mathrm{C}$.

Dois outros fatores climáticos são diretamente relacionados com o crescimento do abacaxizeiro: a umidade relativa do ar, onde um déficit na fase inicial do crescimento pode atrasá-la, estando o ótimo em torno de $75 \%$, e a luminosidade, que em baixos valores pode retardar o crescimento (Cunha, 1999).

Qualquer que seja a técnica de cultura de tecidos utilizada, as plantas obtidas necessitam passar por um período de aclimatização e crescimento até atingirem o tamanho adequado para o plantio definitivo no campo, quando merecem uma avaliação de seu desenvolvimento (Moreira, 2001). Esse período é variável, dependendo do substrato e nutrição, podendo durar de 5 a 10 meses (Reinhardt, 1999; Cunha, 1999; Teixeira et al., 2001; Barroso et al.; 2003).
Barreiro Neto et al. (2002) citam que mudas meristemáticas são de crescimento lento, permanecendo em pré-aclimatização por até 6 meses. Eles encontraram mudas com altura de $24,7 \mathrm{~cm}$ aos 150 dias após plantio (DAP), massa fresca da parte aérea de 106,0 g, número de folhas por planta igual a 21,8 , peso fresco de raiz de $6,7 \mathrm{~g} \mathrm{e}$ comprimento de raiz igual $15,5 \mathrm{~cm}$. Esses autores concluíram que as mudas meristemáticas em viveiro só alcançaram altura e peso necessários para plantio em local definitivo aos 210 DAP.

O objetivo deste trabalho foi avaliar o crescimento foliar e radicular das mudas micropropagadas do abacaxizeiro da casa de vegetação de pré-aclimatação, expondo-as às condições naturais de clima.

\section{MATERIAL E MÉTODOS}

O experimento foi conduzido em casa de vegetação, no Campus do Centro de Ciências Agrárias da Universidade Federal do Espírito Santo, localizado no município de Alegre, Estado do Espírito Santo.

Visando uniformizar terminologias, adotou-se o termo aclimatização para o período de tempo representado pela permanência das mudas em ambiente climatizado do laboratório de cultura de tecidos. E como pré-aclimatação, fase I em casa de vegetação, o período compreendido entre a aclimatização e o transplantio das mudas e, como pré-aclimatação fase II em casa de vegetação, o tempo transcorrido entre o transplantio das mudas e sua retirada deste ambiente e ainda, como aclimatação, o período correspondente à exposição das mudas às condições naturais de clima (fora da casa de vegetação). Por outro lado, esses termos quando citados de outros autores, serão mantidos no seu sentido íntegro.

Neste experimento avaliou-se, durante a fase de pré-aclimatação, fase II em estufa, a melhor idade para retirada das mudas micropropagadas do acabaxizeiro cv. Gold da estufa, aclimatando-as. A estufa possuía cobertura plástica transparente, com espessura de 150 micras e subcobertura de sombrite $50 \%$; suas laterais eram fechadas com clarite $50 \%$.

As mudas foram procedentes do laboratório de cultura de tecidos Biomudas, de Venda Nova do Imigrante-ES e estavam acondicionadas em bandejas de isopor de 200 células, com substrato plantmax hortaliças $\mathrm{HT}^{\circledR}$, com 20 dias de aclimatização. As mudas foram trazidas para a casa de vegetação de 
pré-aclimatação do CCA-UFES, onde permaneceram, durante as fases I e II, recebendo duas regas diárias com duração de 4 minutos cada, às 10:00 h e 18:00 $\mathrm{h}$, através de sistema de microaspersão automatizada com vazão de $140 \mathrm{~L} \mathrm{~h}^{-1}$, com espaçamento entre microaspersores de 2,00 m por 1,00 m. Também, as mudas em processo de aclimatação, receberam o mesmo manejo de irrigação estabelecido para a pré-aclimatação fase II em casa de vegetação. As mudas receberam, durante os primeiros 15 dias de pré-aclimatização fase I, diurnamente, pulverizações com água de 3 em 3 horas.

Para a montagem do experimento, as mudas foram padronizadas por altura, apresentando média de $8,08 \mathrm{~cm}$ e desvio-padrão de $\pm 1,02 \mathrm{~cm}$ e estavam com 32 dias de pré-aclimatação fase I em casa de vegetação.

Os recipientes plásticos usados para transplantio das mudas possuíam volume aproximado de 10,5 litros, com dimensões de 27,0 cm de diâmetro e altura de $18,4 \mathrm{~cm}$.

O substrato foi composto percentualmente (v/v), modificado de Moreira (2001): 50\% de terra de superfície, $30 \%$ de areia lavada e $20 \%$ de esterco bovino, sendo esses materiais peneirados e misturados até sua completa homogeneização, quando foi retirada uma amostra para determinação de atributos químicos, textura e densidade do solo (ds).

De acordo com a interpretação de Dadalto \& Fullin (2007), todos os macronutrientes estão com níveis altos, exceto $\mathrm{P}$ (médio), Ca (baixo) e o $\mathrm{S}$ (não determinado); o pH foi de 7,2 (alcalinidade fraca) e os micronutrientes: $\mathrm{Fe}, \mathrm{Mn}, \mathrm{Cu}$ (altos); $\mathrm{B}$ (baixos), Zn (médio) e M.O. (média). A análise textural apresentou: $71,88 \%$ de areia, $16,73 \%$ de argila e $11,38 \%$ de silte, sendo classificado como textura média (EMBRAPA, 1999) e a densidade do solo foi de $1,17 \mathrm{~g} \mathrm{~cm}-3$, determinados segundo método Embrapa (1997).

Os recipientes depois de cheios foram colocados na casa de vegetação, sobre bancadas, onde permaneceram por um período de 50 dias até a data do transplantio, recebendo irrigações diárias conforme programação prevista para o sistema.

A adubação utilizada foi adaptada de Moreira (2001) e recomendada por Malavolta (1980), com o uso de dosagens de NPK para fertilização de vasos: 0,30 g N; 0,20 g P e 0,15 g K por cada $\mathrm{kg}$ de substrato, sendo o P todo no plantio e NK parcelado durante o crescimento das plantas, esses valores foram ajustados para a massa de substrato contido nos recipientes. Mensalmente, a partir de 30 dias após transplantio, foi realizada adubação foliar com ouro verde tradicional completo ${ }^{\circledR}$ (macro e micronutrientes) na dosagem de $3,0 \mathrm{~g} \mathrm{~L}^{-1}$.

$\mathrm{O}$ experimento foi montado em esquema de parcela subdividida no delineamento inteiramente casualizado (DIC), com 4 repetições, onde cada recipiente com uma muda correspondeu a uma unidade experimental. As parcelas foram constituídas pelas 5 idades (IDA) de retirada das mudas da pré-aclimatação fase II em casa de vegetação: 0; 1 ; $2 ; 3$ e 4 meses e a testemunha que permaneceu por 5 meses nesse ambiente, respectivamente denominadas de: $\mathrm{IDA}_{0}, \mathrm{IDA}_{1}, \mathrm{IDA}_{2}, \mathrm{IDA}_{3}, \mathrm{IDA}_{4}$ e IDA (testemunha) e as subparcelas foram formadas por avaliações aos: 0; 30; 60; 90; 120 e 150 dias após o transplantio (DAT).

A $\mathrm{IDA}_{0}$, que a partir da instalação do experimento permaneceu fora da casa de vegetação até a avaliação final, foi composta por 20 mudas de suas respectivas épocas de avaliação e mais 4 mudas de reserva.

As características avaliadas foram: área foliar por planta (AFO), massa seca da parte aérea (MSA), massa seca da raiz (MSR) e comprimento da maior raiz (CMR). A MSA e MSR foram mensuradas através de balança analítica de precisão de 0,0001 g. Para mensuração das massas secas, as amostras permaneceram em estufa de circulação forçada de ar por 72 horas, a $70{ }^{\circ} \mathrm{C}$. A característica CRM foi medida, com régua graduada em milímetros, a partir do colo da planta até a extremidade da maior raiz. A AFO foi determinada através do método das pesagens, conforme metodologia descrita por Benincasa (2003). A MST foi calculada pela soma da MSA com MSR. A partir dessas informações foram calculadas características morfofisiológicas: razão de massa seca da parte aérea (RMSA) pela Equação 1 e razão de área foliar (RAF) pela Equação 2; expessões descritas por Benincasa (2003), sendo que suas avaliações foram feitas em meses após o transplantio (MAT).

$$
R M S A=\frac{M S A}{M S T} \quad \text { Equação } 1
$$

em que:

MSA é a massa seca da parte aérea em g e MST é a massa seca total em g, ficando a unidade de razão de massa seca da parte aérea em $\mathrm{g} \mathrm{g}^{-1}$. 


$$
R A F=\frac{A F O}{M S T}
$$

em que:

$A F O$ é a área foliar em $\mathrm{cm}^{2} \mathrm{e} M S T$ a massa seca total em g, ficando a unidade de $R A F \mathrm{em} \mathrm{cm}^{2} \mathrm{~g}^{-1}$.

Os dados experimentais foram submetidos à análise de variância e quando significativos, os valores das médias para IDA, isoladamente ou em interação com DAT foram comparados pelo teste de Scott Knott a 5\% de probabilidade, utilizando o software SAEG 9.0. Para o fator quantitativo época de avaliação (DAT), tanto seu efeito isolado ou a interação com IDA, foi feito regressão e os modelos foram escolhidos com base na significância dos coeficientes de regressão, utilizando-se o teste t de Student, adotando-se o nível de 5\% de probabilidade e, também, pelo maior coeficiente de determinação $\left(\mathrm{R}^{2}\right)$.

\section{RESULTADOS E DISCUSSÃO}

Observa-se na Figura 1 os valores médios da área foliar por muda, para cada idade de retirada da casa de vegetação, dentro de cada época de avaliação. Observa-se que as diferenças começam a aparecer já aos 90 dias de avaliação, mostrando o menor desempenho para $\operatorname{IDA}_{0}$, o qual permanece até a avaliação aos 150 DAT. A IDA 1 mostra superioridade na avaliação final do experimento, não diferindo significativamente da testemunha (IDA 5 ). Esse resultado vem de encontro com o trabalho de Silva et al. (1995) sobre aclimatação de espécies com diferentes rusticidades. Eles afirmaram que a área foliar depende da espécie e idade de enraizamento, pois, a espécie que melhor se aclimatou não foi aquela de maior desenvolvimento foliar. Observase, na Figura 2, que todas as idades de retirada da casa de vegetação, apresentam comportamento de crescimento exponencial positivo com o tempo, embora haja diferenças de desempenho entre elas, sendo que a IDA $\mathrm{ID}_{0}$ a $\mathrm{IDA}_{4}$ apresentam o menor desempenho e a IDA ${ }_{1}$ o maior. Rebolledo Martinez et al. (2005), em experimento com 3 cultivares (Champaka, Oro e Smooth Cayenne) sob cultivo com e sem cobertura plástica do solo, encontraram curvas de crescimento de área foliar, para todas as cultivares e ambientes, até os 10 meses do plantio, semelhantes às deste trabalho.

A testemunha $\left(\mathrm{IDA}_{0}\right)$ apresenta o menor valor de massa seca da parte já a partir de 90 dias, perdurando

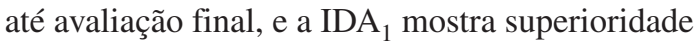
sobre as demais no final da avaliação (Figura 3). Observa-se em todos tratamentos um comportamento de crescimento exponencial positivo com o tempo para todas as idades, sendo que a $\mathrm{IDA}_{0}$ apresenta o menor desempenho e $\mathrm{IDA}_{1}$ o maior (Figura 4).

Os resultados para massa seca de raiz estão nas Figuras 5 e 6. Na Figura 5, a IDA 1 (1,06 g) e IDA $(0,93 \mathrm{~g})$ e na testemunha - $\mathrm{IDA}_{5}(0,82 \mathrm{~g})$ apresentam os maiores valores médios aos 150 DAT, não diferindo significativamente entre si. Desse modo, é provável que os resultados encontrados, estejam

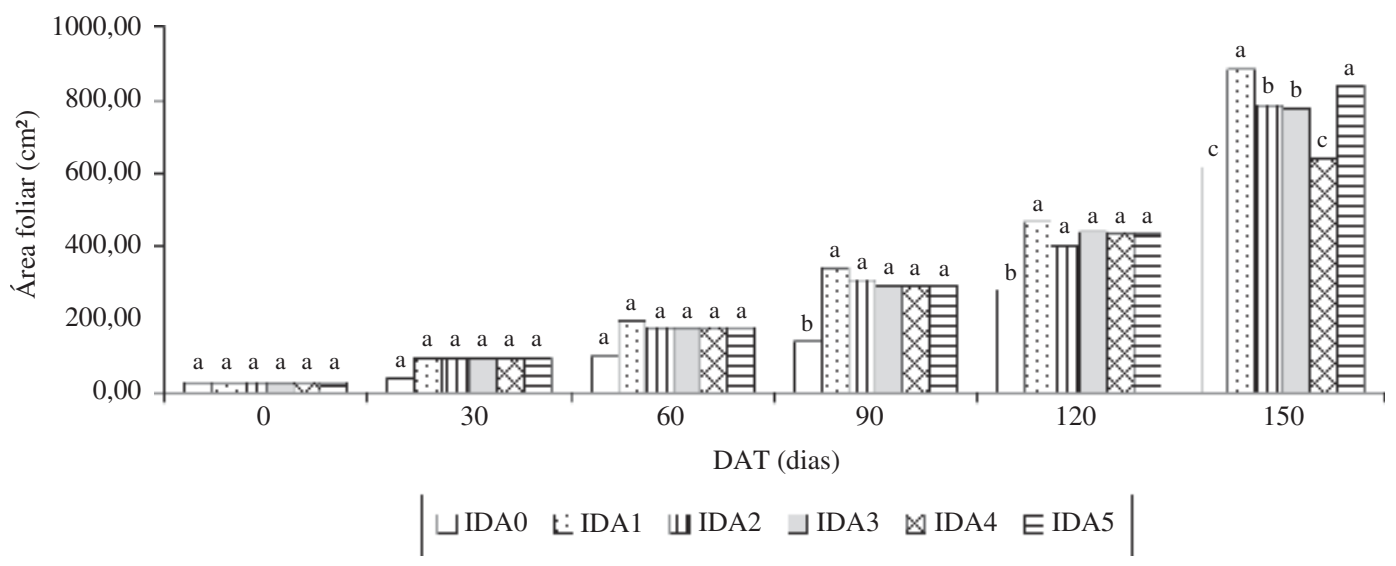

Figura 1. Área foliar das mudas do abacaxizeiro cv. Gold em cada nível dos dias após transplantio (DAT) para as idades de retirada da casa de vegetação (IDA). 


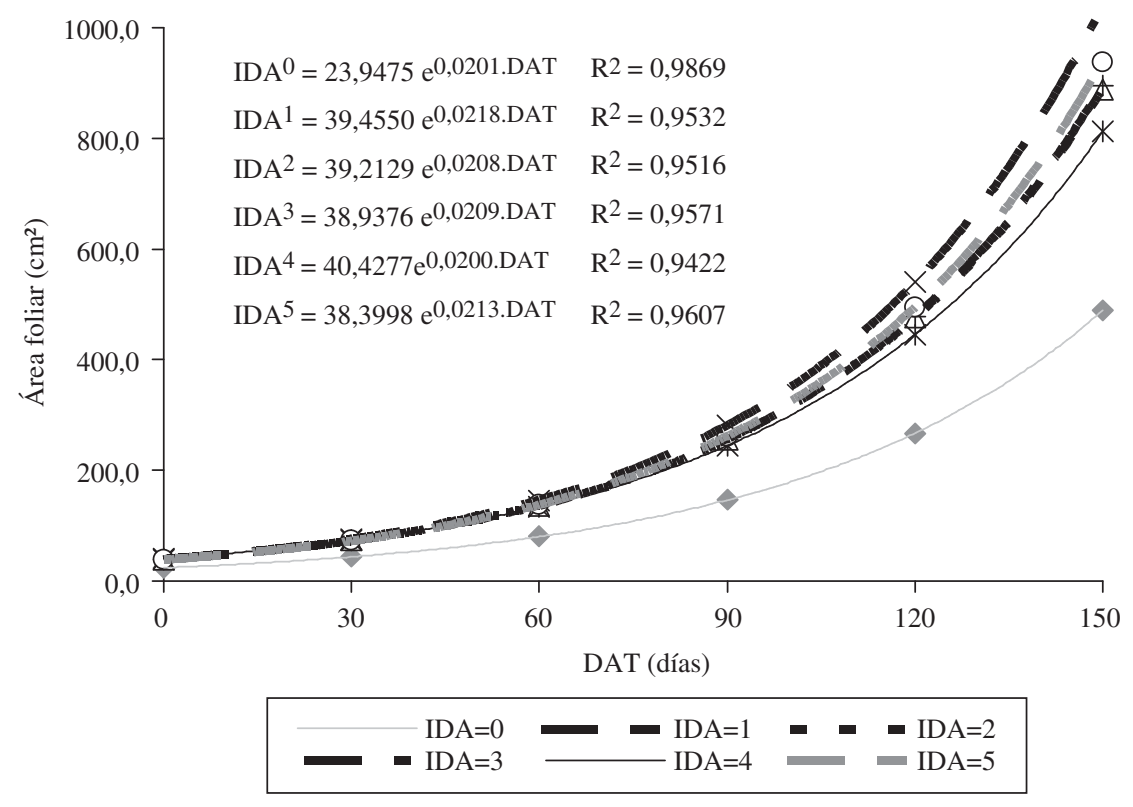

Figura 2. Estimativa da área foliar das mudas do abacaxizeiro cv. Gold em função dos dias após transplantio (DAT) para as respectivas idades de retirada da casa de vegetação (IDA).

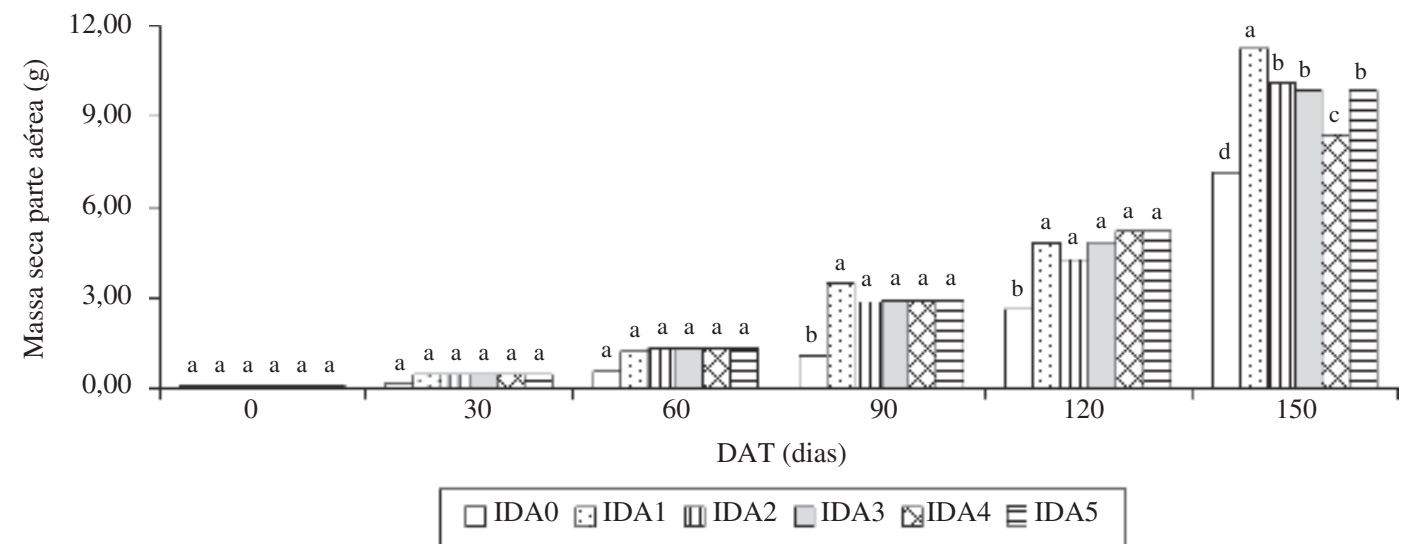

Figura 3. Massa seca da parte aérea das mudas do abacaxizeiro cv. Gold para cada nível dos dias após transplantio (DAT) para as idades de retirada da casa de vegetação (IDA).

associados ao melhor desenvolvimento do sistema radicular das mudas fora da casa de vegetação, decorrentes da maior exposição à radiação solar, que elevou a temperatura do substrato, concordando com Cunha (1999) onde este afirma que com a elevação da temperatura no meio enraizante há aumento do peso da planta. Na Figuras 6 é observado o crescimento exponencial positivo para massa seca da raiz, mostrando o maior desempenho da $\mathrm{IDA}_{1}$ e menor da $\mathrm{IDA}_{0}$.
A média de comprimento da maior raiz para cada idade de retirada da casa de vegetação, apresentou um comportamento diferenciado entre tratamentos somente a partir dos 90 DAT, com melhor desempenho para $\mathrm{IDA}_{1}, \mathrm{IDA}_{3}, \mathrm{IDA}_{4}$ e $\mathrm{IDA}_{5}$ que não diferem significativamente entre si, já IDA $_{0} \mathrm{e}$ $\mathrm{IDA}_{2}$ apresentaram resultados inferiores. Ao final do experimento 150 DTA a melhor idade para retirada das plantas da cassa de vegetação é IDA $_{5}$ e a pior é $\mathrm{IDA}_{4}$ (Figura 7) estando os resultados de acordo 


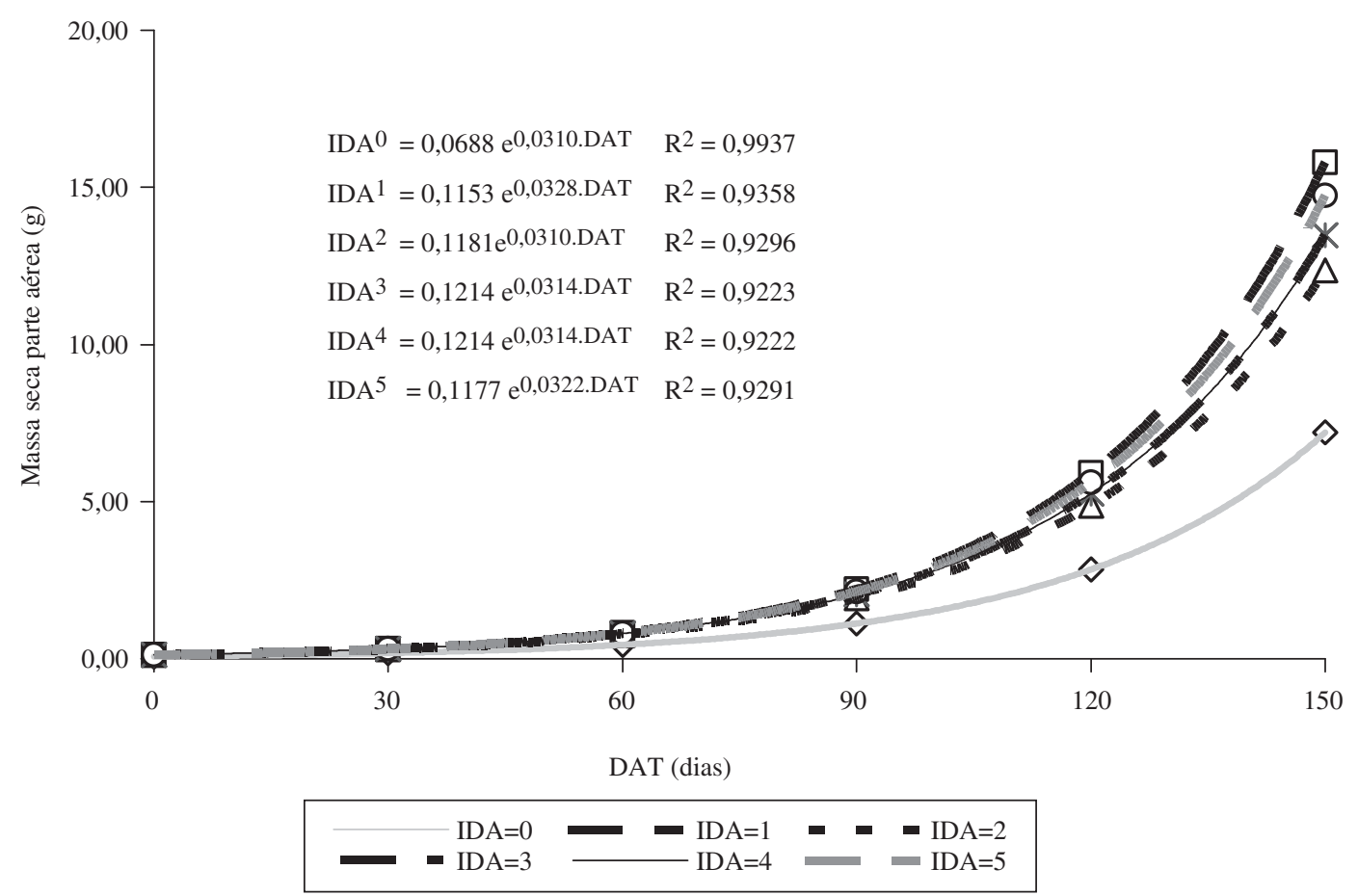

Figura 4. Estimativa da massa seca da parte aérea das mudas do abacaxizeiro cv. Gold em função dos dias após transplantio (DAT) para as respectivas idades de retirada da casa de vegetação (IDA).

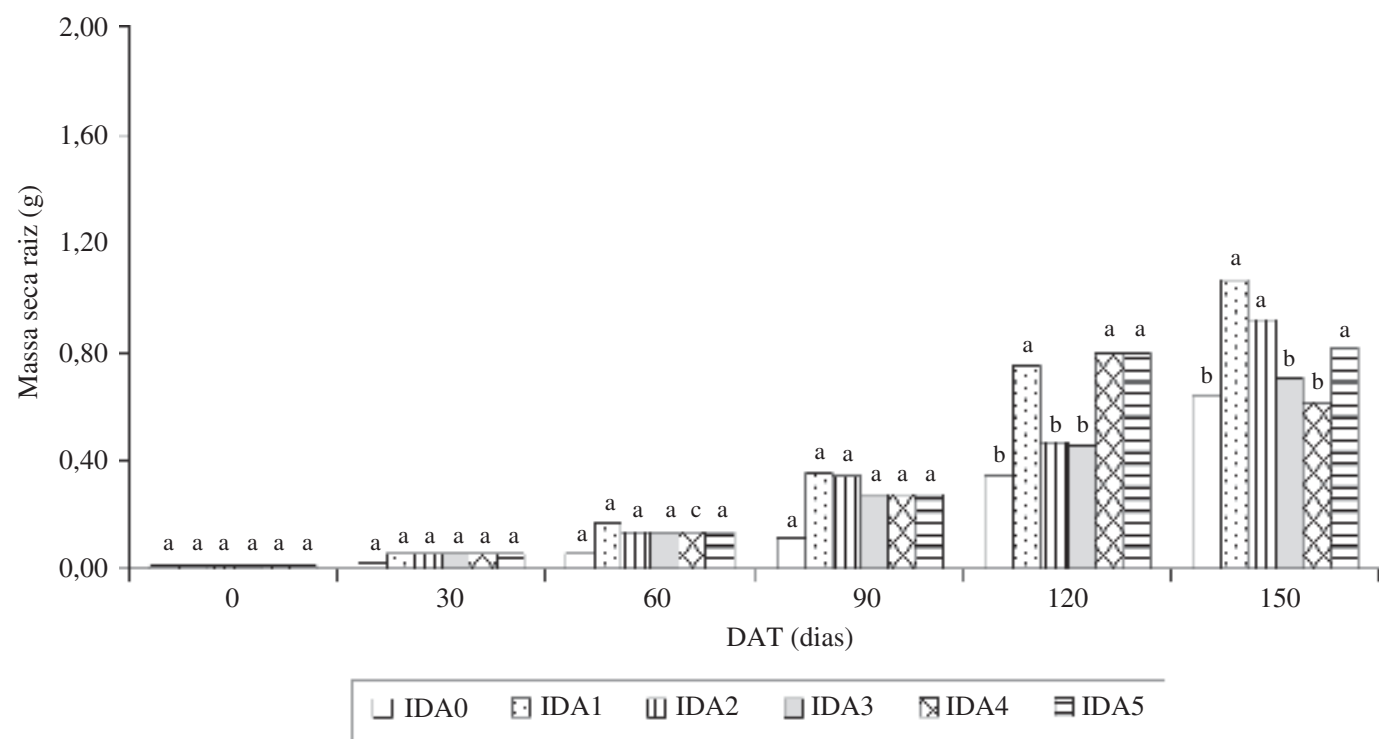

Figura 5. Massa seca da raiz de mudas de abacaxizeiro cv. Gold em cada nível dos dias após transplantio (DAT) para as idades de retirada da casa de vegetação (IDA). 


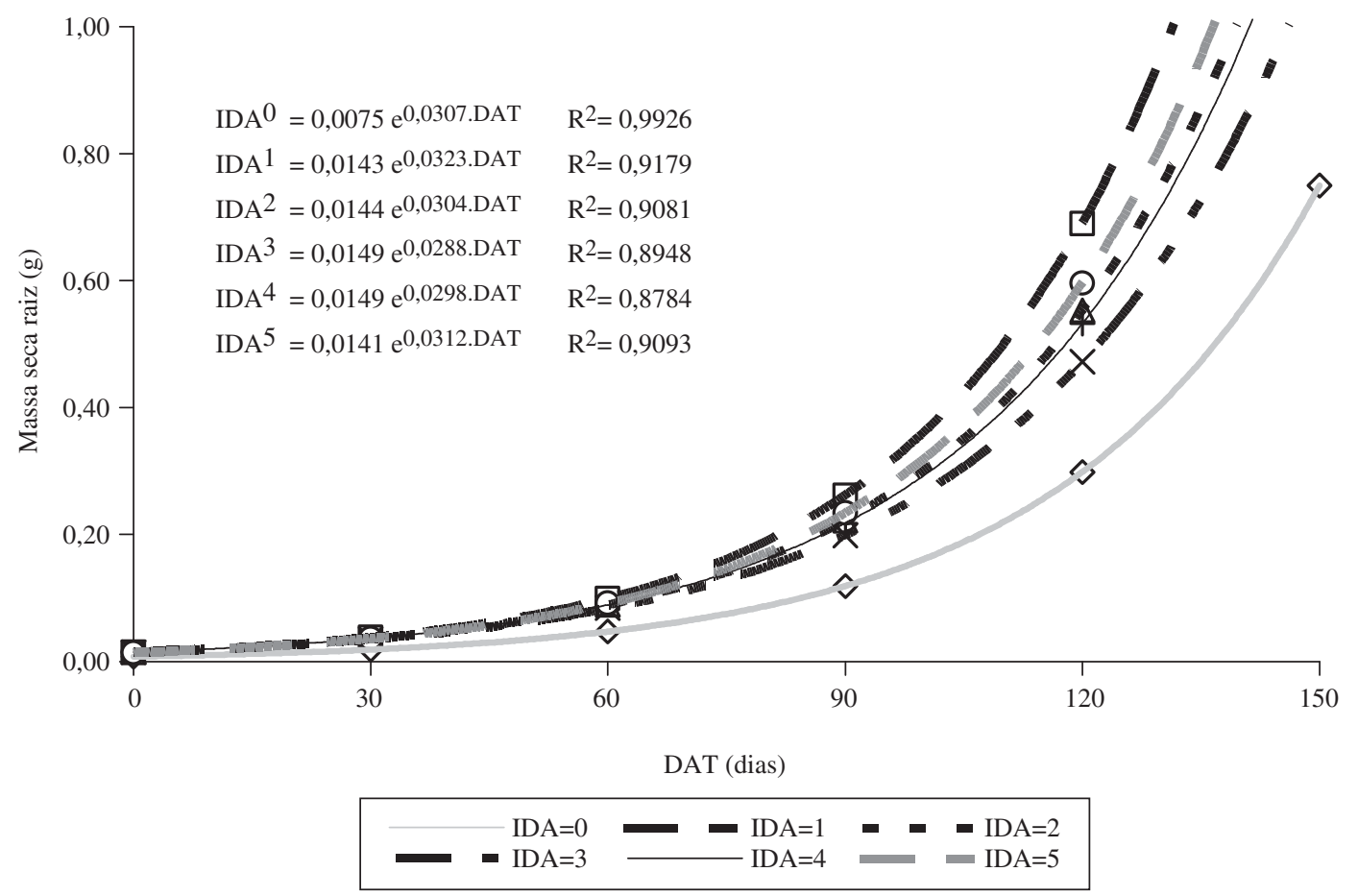

Figura 6. Estimativa da massa seca da raiz das mudas do abacaxizeiro cv. Gold em função dos dias após transplantio (DAT) para as respectivas idades de retirada da casa de vegetação (IDA).

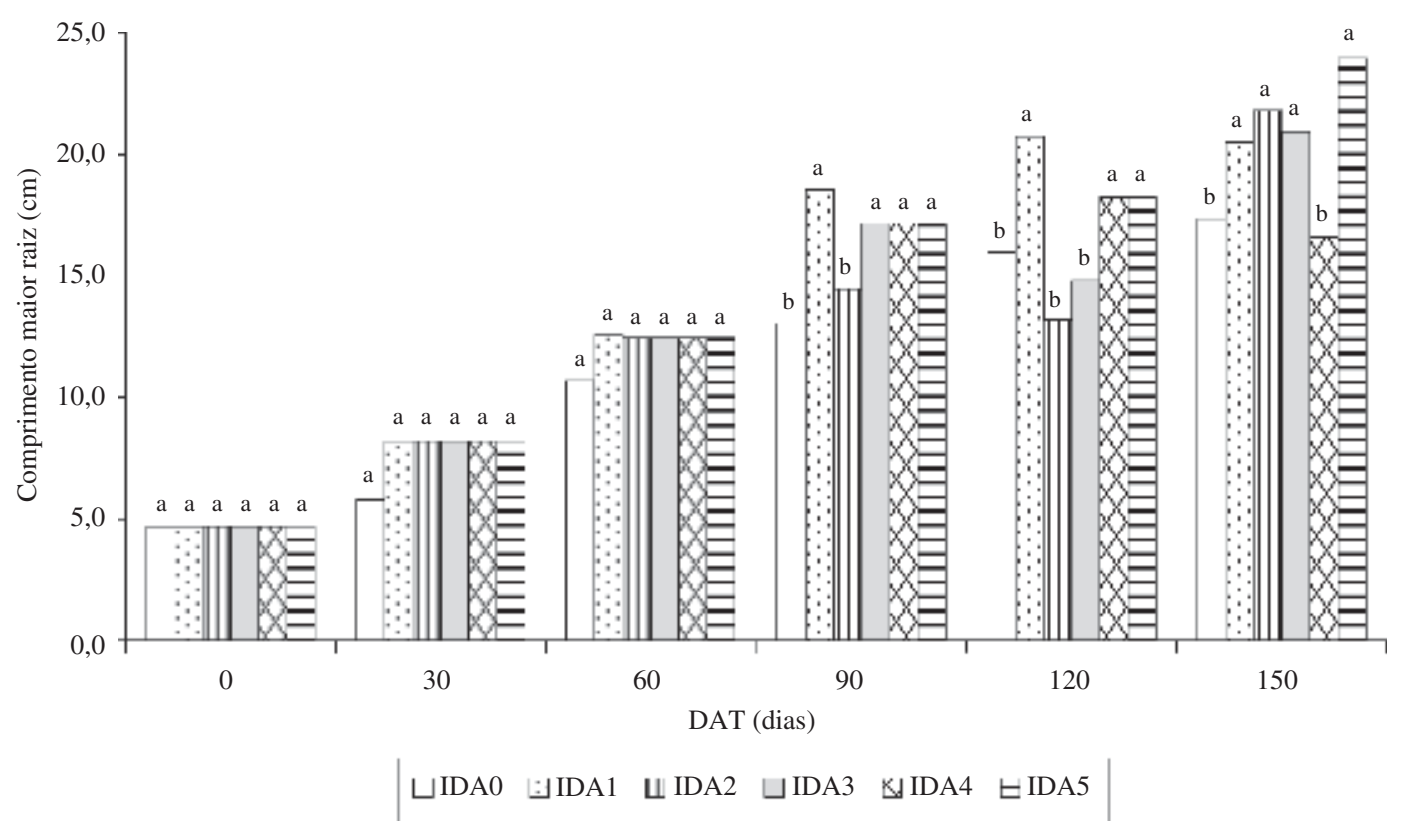

Figura 7. Comprimento da maior raiz das mudas do abacaxizeiro cv. Gold em cada nível dos dias após transplantio (DAT) para as idades de retirada da casa de vegetação (IDA). 
com as observações de Cunha (1999). Observa-se, pela Figura 8, que todas as idades apresentam um comportamento semelhante de crescimento, de forma crescente positiva com o tempo. Observase que o período de realização do experimento foi caracterizado por declínio da temperatura média a partir do mês de plantio, permanecendo até a avaliação final, estando de acordo com Cunha (1999), quando cita as influências das baixas temperaturas e a influência do fotoperíodo sobre o crescimento do abacaxizeiro.

A razão de massa seca da parte aérea (RMSA) é um componente fisiológico que expressa a fração da massa seca produzida pela parte aérea da planta e não translocada para as raízes na forma de fotoassimilados. A maior ou menor translocação pode ser uma característica genética, mas, está sob influência de variáveis ambientais (BENINCASA, 2003). Com média de $0,90 \mathrm{~g} \mathrm{~g}^{-1}$ para todas as idades (Tabela 1) e com $\hat{Y}=\bar{Y}=0,90 \mathrm{~g} \mathrm{~g}^{-1} \mathrm{em}$ todas as épocas de avaliações, demonstra-se que $90 \%$ dos carboidratos produzidos pelas folhas são utilizados para crescimento e produção da parte aérea, estando estes resultados de acordo com Giacomelli (1982) ao afirmar que em plantas adultas, até a diferenciação floral, a folhagem representa $90 \%$ de seu peso total. Silva et al. (1998), em trabalho de adubação com mudas micropropagadas da cv. Primavera em fase de aclimatação, afirmaram que os nutrientes absorvidos foram direcionados para a parte aérea, em detrimento do crescimento do sistema radicular.

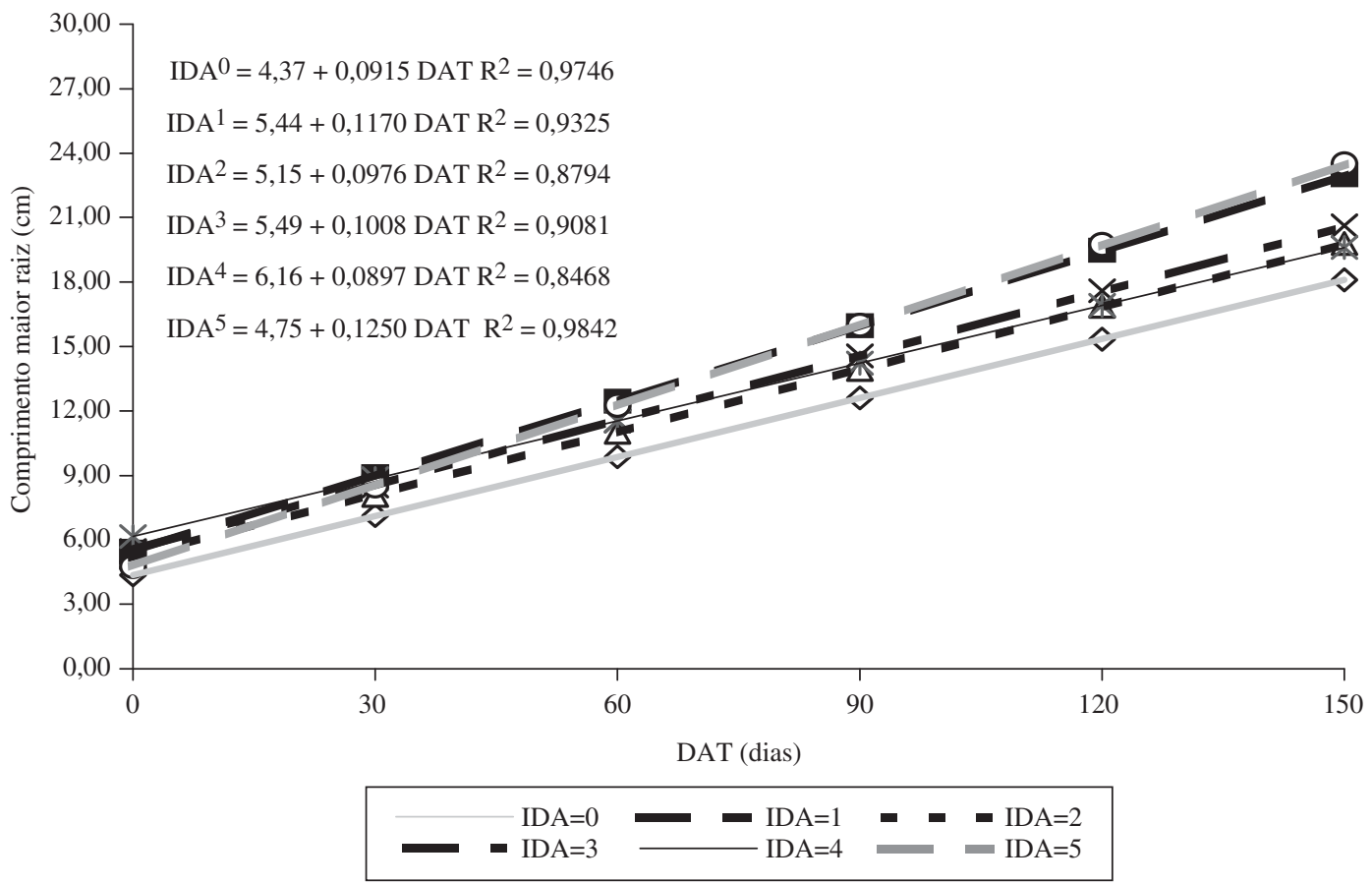

Figura 8. Estimativa do comprimento da maior raiz das mudas do abacaxizeiro cv. Gold em função dos dias após transplantio (DAT) para as respectivas idades de retirada da casa de vegetação (IDA).

Tabela 1

Valor médio da razão de massa seca da parte aérea (RMSA) para todas as idades de retirada das mudas do abacaxizeiro cv. Gold da casa de vegetação

\begin{tabular}{|c|c|c|c|c|c|c|}
\hline Característica & Unidade & Média & Desvio padrão & Valor máximo & Valor mínimo & CV (\%) \\
\hline RMSA & $\mathrm{g} \mathrm{g}^{-1}$ & 0,90 & 0,02 & 0,95 & 0,80 & 2,56 \\
\hline
\end{tabular}


Verifica-se, pela Tabela 2, que a componente morfofisiológica razão de área foliar, a qual mostra a eficiência da planta em produzir material orgânico para seu crescimento e desenvolvimento, somente apresenta diferença significativa para a $\mathrm{IDA}_{0}$, a qual obteve o maior valor médio no período em estudo, mostrando-se, dessa forma, menos eficiente. Na Figura 9, observa-se o aumento da eficiência das mudas com o passar dos meses após o transplantio, pois, vai diminuindo a área foliar requerida para produção de $1,00 \mathrm{~g}$ de massa seca.

Médias com mesma letra não diferem significativamente entre si pelo teste de Scott Knott a 5\%.
No presente experimento, registra-se um alto índice de sobrevivência das mudas que compunham a $\mathrm{IDA}_{0}$, em que do total de 32 mudas que permaneceram durante todo o tempo da experimentação fora do ambiente protegido, expostas às condições naturais de clima, apenas 2 morreram, perfazendo uma mortalidade de $6,25 \%$, resultado este que concorda com aqueles obtidos por Moreira (2001) e Moreira et al. (2006), que obtiveram valores semelhantes.

Observou-se também que até aos sessenta dias após o transplantio, após ocorrência de chuvas fortes, as mudas que estavam fora da casa de vegetação, em aclimatação, necessitavam de esguicho de água para retirada do substrato que caía sobre a roseta foliar.

Tabela 2

Valores médios da razão de área foliar (RAF) das mudas do abacaxizeiro cv. Gold para as idades de retirada da casa de vegetação (IDA)

\begin{tabular}{|c|c|c|c|c|c|c|}
\hline IDA (mês) & IDA $_{\mathbf{0}}$ & IDA $_{\mathbf{1}}$ & $\mathbf{I D A}_{\mathbf{2}}$ & $\mathbf{I D A}_{\mathbf{3}}$ & $\mathbf{I D A}_{\mathbf{4}}$ & IDA $_{\mathbf{5}}$ \\
\hline $\mathrm{RAF}\left(\mathrm{cm}^{\mathbf{2}} \mathrm{g}^{1}\right)$ & $176,2027 \mathrm{a}$ & $165,398 \mathrm{~b}$ & $162,5988 \mathrm{~b}$ & $162,8103 \mathrm{~b}$ & $160,3168 \mathrm{~b}$ & $161,5605 \mathrm{~b}$ \\
\hline
\end{tabular}

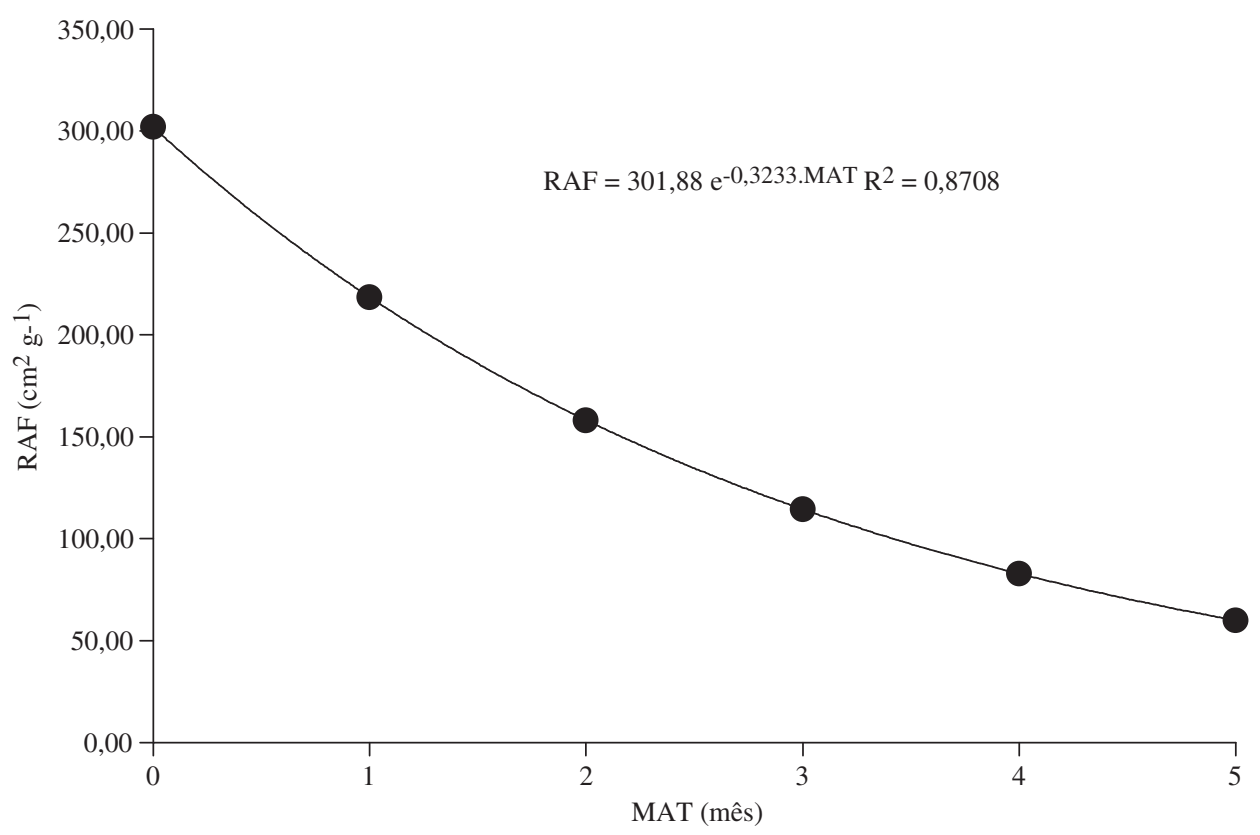

Figura 9. Estimativa da razão de área foliar (RAF) das mudas do abacaxizeiro cv. Gold em função dos meses após transplantio (MAT) para as idades de retirada da casa de vegetação. 


\section{CONCLUSÕES}

Nas condições em que foi realizado este experimento, pode-se concluir que:

- para todas as características avaliadas, a permanência das mudas em casa de vegetação além de 2 meses de idade após transplantio,

\section{REFERÊNCIAS}

ALBUQUERQUE, C. C.; CAMARA, T. R.; MENEZES, M.; WILLADINA, L.;MEUNIER, I.; ULISSES, C. 2000. Cultivo in vitro de ápices caulinares de abacaxizeiro para limpeza clonal em relação à fusariose. Scientia agrícola, 57(2):363-366.

BARREIRO NETO, M.; SANTOS, E. S.; FRANCO, C. F. O.; LACERDA, J. T.; CARVALHO, R. A. 2002. Crescimento de mudas meristemáticas e filhotes de abacaxizeiro em viveiro. In: BARREIRO NETO, M. SANTOS, E. S. (Ed.). Abacaxi: da agricultura familiar ao agronegócio. João Pessoa. EMEPA-PB, p. 59-71.

BARROSO, P. A. V.; MOURA, G. E. D. D.; BRITO, L. K. F.; MARTINS, C. P.; MACEDO, C. E. C.; LOPES, D. B.; ALOUFFA, M. A. I. 2003. Efeito do cultivo in vitro na presença de $\mathrm{NaCl}$ em plantas de abacaxizeiro na fase de aclimatação. Revista Brasileira de Engenharia Agrícola e Ambiental, Campina Grande: PB, 7(3):473-477.

BENINCASA, M. M.P. 2003. Análise de crescimento de plantas: noções básicas. 2. ed. Jaboticabal: FUNEP, 2003. 41 p.

CABRAL. J. R. S.; COPPENS D'EECKENBRUGG, G. Abacaxizeiro.2002. In: BRUCKNER, C. H. (Ed.). Melhoramento de fruteiras tropicais. Viçosa, MG: UFV, p. 37-61.

CUNHA, G. A. P. 1999. Aspectos agroclimáticos. In: CUNHA, G. A. P.; CABRAL, J. R. S.; SOUZA, L. F. S. (Org.). O abacaxizeiro: cultivo, agroindústria e economia. Brasília: EMBRAPA, p. 53-66.

DADALTO, G. G.; FULLIN, E. A. 2007. (Ed.). Manual de recomendação de calagem e adubação para o Estado do Espírito Santo. Vitória, ES: SEEA/INCAPER, p.305.

EMBRAPA - Empresa Brasileira de Pesquisa Agropecuária. 1997. Manual de métodos de análise de solo. 2. ed. Rio de Janeiro: EMBRAPA Solos, 212 p.

EMBRAPA - Empresa Brasileira de Pesquisa Agropecuária. 1999. Sistema brasileiro de classificação de solos. Brasília: EMBRAPA Serviço de Produção de Informação. 1999. p. 347-348.

GUERRA, M. P.; NODARI, R. O. 2006. Material didático de apoio à disciplina de Biotecnologia. Disponível em: não apresenta vantagens comparativas com $\mathrm{IDA}_{1}$ e IDA

- a diferenciação quanto à massa seca da parte aérea ocorre a partir de 90 dias, quanto a massa seca da raiz esta só ocorre os 120 dias;

- a diferenciação do comprimento da maior raiz ocorre a partir de 90 dias.

$<$ http://www.cca.ufsc.br/lfdgv/Apostila.htm>. Acesso em: 08 out. 2006

GIACOMELLI, E. J. 1982. Expansão da abacaxicultura no Brasil. Campinas: Fundação Cargill, p. 28-29.

MALAVOLTA, E. 1980. Elementos de nutrição mineral de plantas. Piracicaba: CERES, p. 219-251.

MOREIRA, M. A. 2001. Produção e aclimatização de mudas micropropagadas de abacaxizeiro: Ananas comosus (L) Merrill cv. Pérola. Lavras: 2001. 81 f. Tese (Doutorado em Fitotecnia) - UFLA, 2001.

MOREIRA, M. A.; CARVALHO, J. G.; PASCOAL, M.; FÁGUAS, C. B.; SILVA, A. B.2006. Efeito de substratos na aclimatização de mudas micropropagadas de abacaxizeiro cv. Pérola. Ciência e Agrotecnologia, Lavras, 30(5):875-879.

REBOLledO MARTINEZ, A.; PÉREZ, A. L. del A.; ROMÁN, A. E. B. REBOLLEDO MARTINEZ, L. 2005. Growth analysis for three pineapple cultivars grown on plastic mulch and bare soil. Interciencia. Caracas (Venezuela), 30(12):758-763.

REINHARDT, D. H. R. C. CUNHA, G. A. P. 1999. Métodos de propagação. In: CUNHA, G. A. P.; CABRAL, J. R. S.; SOUZA, L. F. S. (Org.). O abacaxizeiro: cultivo, agroindústria e economia. Brasília, DF: EMBRAPA, p. 105-138.

SILVA, A. T.; PASQUAL, M.; ISHIDA, J. S.; ANTUNES, L. E. C. 1995. Aclimatação de plantas provenientes da cultura in vitro. Pesquisa Agropecuária Brasileira, Brasília, 30(1):49-53.

SILVA, A. B.; PASQUAL, M.; MOREIRA, M. A.; MACIEL, A. L. R.; CAVALCANTE-ALVES, J. M.; BARRETTO, A. P. 1998. Aclimatação de brotações de abacaxi (Ananas comosus (L.) produzidas in vitro: ação de agromix ${ }^{\circledR}$, húmus e Kelpak ${ }^{\circledR}$. Revista da Universidade de Alfenas. Alfenas, 4:107-110.

TEIXEIRA, J. B.; CRUZ, A. R. R.; FERREIRA, F. R.; CABRAL, J. R. S. 2001. Biotecnologia aplicada à produção de mudas: produção de mudas micropropagadas de abacaxi. Biotecnologia Ciência \& Desenvolvimento. Brasília, amo 9, 3. Disponível em: <http://biotecnologia.com.br/revista/ bio19_8.pdf>. Acesso em: 10 jan. 2007. 